Case Report

\title{
Spontaneous Regression of Cardiac Rhabdomyoma Presenting as Severe Left Ventricular Inlet Obstruction in a Neonate with Tuberous Sclerosis
}

\author{
Eun Song Song $\mathbb{D}^{D}$, Kumi Jeong, Gun Kim, In Ji Hwang, Mi-Ji Lee, Hwa Jin Cho, and \\ Young Kuk Cho \\ Department of Pediatrics, Chonnam National University Medical School, Chonnam National University Hospital, Gwangju, \\ Republic of Korea \\ Correspondence should be addressed to Young Kuk Cho; youngcx@hanmail.net
}

Received 4 June 2017; Accepted 27 November 2017; Published 28 January 2018

Academic Editor: Assad Movahed

Copyright (c) 2018 Eun Song Song et al. This is an open access article distributed under the Creative Commons Attribution License, which permits unrestricted use, distribution, and reproduction in any medium, provided the original work is properly cited.

\begin{abstract}
Cardiac rhabdomyoma can be subclinical or have a fatal presentation according to the onset age and involved site, size, and degree of invasion. Although most cardiac rhabdomyomas become smaller with time, emergency intervention is indicated when severe obstruction has occurred. In this report, we describe the spontaneous regression of a large cardiac rhabdomyoma $(20.5 \times 15.6 \mathrm{~mm})$ presenting as severe left ventricular inlet obstruction in a neonate with tuberous sclerosis. Although a cardiac rhabdomyoma can be large enough to induce left ventricular inlet obstruction, conservative treatment without aggressive surgical intervention can be considered if the hemodynamic condition does not deteriorate.
\end{abstract}

\section{Introduction}

Rhabdomyoma is the most common cardiac tumor in infants and children and is reported in up to $50-64 \%$ of infants with tuberous sclerosis $[1,2]$. Its expression ranges from subclinical to fatal presentation, according to the onset age and the site, size, and degree of invasion [3]. Although rhabdomyomas become smaller with time, when severe obstruction induces hemodynamic instability or a rhythm abnormality, emergency intervention is indicated [4-6]. Rhabdomyoma causing left ventricular $(\mathrm{LV})$ inlet obstruction can necessitate an emergency operation [3, 7-10]. However, there is no recorded report of spontaneous resolution of a huge cardiac rhabdomyoma causing LV inlet obstruction. We report a case of spontaneous regression of a large symptomatic cardiac rhabdomyoma presenting as severe LV inlet obstruction, occupying $75-90 \%$ of the mitral valve (MV) annulus in a neonate with tuberous sclerosis.

\section{Case Presentation}

A male infant was born at 39 weeks of gestation by vaginal delivery to a healthy 35 -year-old female. There was no family history of congenital heart disease or tuberous sclerosis. At 31 weeks of gestation, a fetal echocardiogram revealed a large, solitary LV mass and multiple right ventricular (RV) masses. The delivery was uneventful. The Apgar score was 10 at both 1 and 5 minutes. Birth weight of $3,450 \mathrm{~g}$, length of $51.0 \mathrm{~cm}$, and head circumference of $35.5 \mathrm{~cm}$ were normal. Transcutaneous oxygen saturation was $95 \%$ on room air, heart rate was $132 \mathrm{bpm}$, respiratory rate was $48 /$ minute, arterial pressure was $62 / 38 \mathrm{mmHg}$, a grade $2 / 6$ mid-diastolic rumbling murmur was heard at the left sternal border, and there were no skin lesions. Chest X-ray showed mild cardiomegaly with increased pulmonary vascular markings. Transcranial ultrasonography was normal.

Two-dimensional echocardiographic examination revealed a large solitary tumor measuring $20.5 \times 15.6 \mathrm{~mm}$ and occupying $75-90 \%$ of the mitral annulus (Figures 1(a)-1(c)). This tumor was attached to the anterior leaflet of the MV, causing LV inlet obstruction. The peak velocity through the MV was $1.66 \mathrm{~m} / \mathrm{s}$ (Figure 1(d)). Right atrial and RV dilatation and pressure overload secondary to pulmonary hypertension were observed (Figure 1(e)). The peak jet velocity through the regurgitant tricuspid valve was $4.13 \mathrm{~m} / \mathrm{s}$ (Figure 1(f)). Mild mitral 


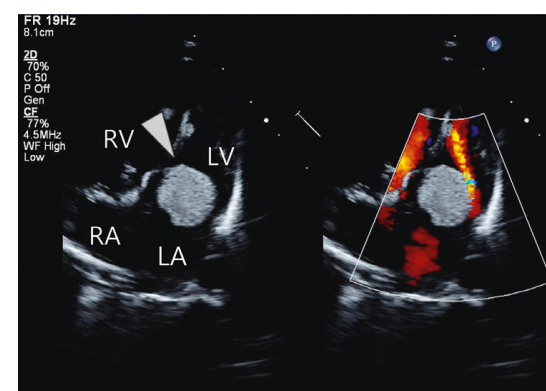

(a)

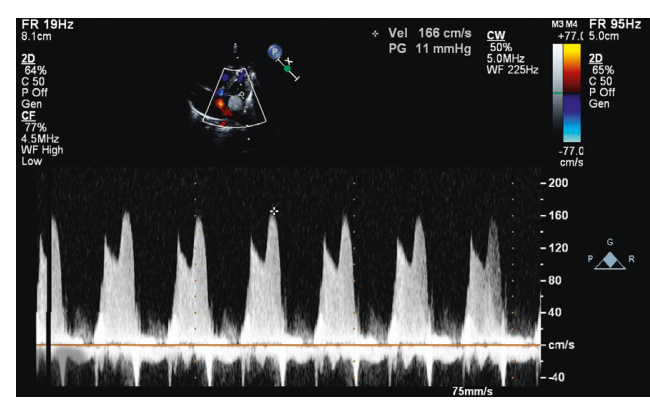

(d)


(b)

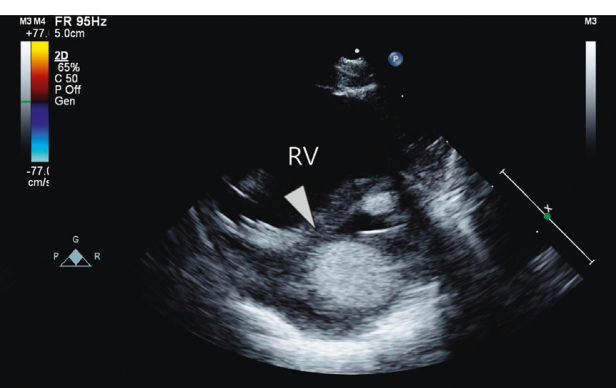

(c)

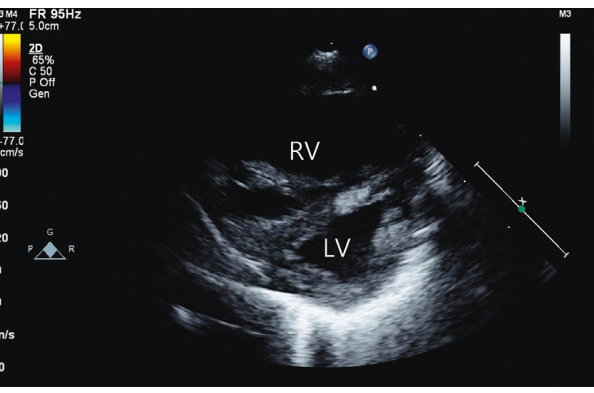

(e)

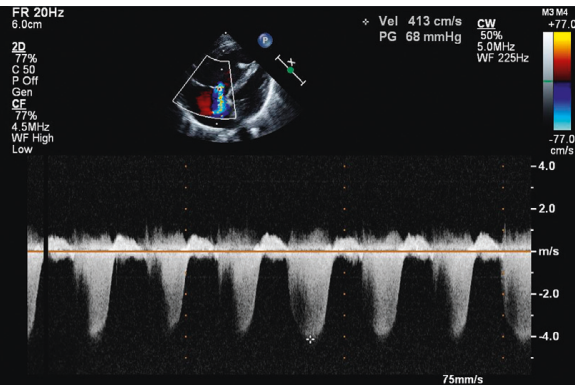

(f)

Figure 1: Two-dimensional echocardiography shows a large rhabdomyoma (arrowhead), $20.5 \times 15.6 \mathrm{~mm}$ in diameter, occupying $75-90 \%$ of the mitral annulus, in addition to multiple small tubers in both ventricles and the left ventricular outflow tract after birth in apical 4-chamber (a), parasternal long-axis (b), and parasternal short-axis (c) views. Right atrial, right ventricular (RV), and left atrial dilatation were also observed. Pulse Doppler echocardiography showed a peak velocity through the mitral valve of $1.66 \mathrm{~m} / \mathrm{s}$ (d). RV dilatation and pressure overload secondary to pulmonary hypertension were observed in a parasternal, end-diastolic short-axis view (e). The peak velocity through the tricuspid valve was $4.13 \mathrm{~m} / \mathrm{s}$ (f).

regurgitation (MR), left atrial (LA) enlargement without LV dilatation, and multiple small tubers in both ventricles and the LV outflow tract were observed (Figures 1(a)-1(c)). LV ejection fraction was normal at $67.2 \%$. Although the newborn had mild subcostal chest retractions, his vital signs were stable; therefore, inotropes and oxygen were not provided. At $5 \mathrm{~h}$ of age, paroxysmal supraventricular tachyarrhythmia at $240 \mathrm{bpm}$ developed. Because intermittent supraventricular tachyarrhythmia with desaturation and irritability continued, repeated doses of adenosine were administered intravenously to restore sinus rhythm. Digoxin was started for long-term management and the tachyarrhythmia resolved. Genetic analysis was performed to detect mutations of tuberous sclerosis complex (TSC) 1 and 2 genes. TSC1 mutation was absent, but a TSC2 mutation (c.5161-1G>C) was detected. Ophthalmic examination revealed a jagged-edged, linear depigmented retina in the right eye. During the 14-day hospital stay, blood pressure was well maintained without inotropes, tachypnea improved, the frequency of breastfeeding increased, and weight gain was observed. Followup chest X-ray showed regression of cardiomegaly and pulmonary vascular markings. Follow-up echocardiography demonstrated decreased MR and pulmonary hypertension and normal systolic LV function. The infant was discharged with only digoxin to prevent arrhythmias.

At 40 days of age, symptoms and signs associated with LV inlet obstruction and tachyarrhythmia were absent. Echocardiography showed good LV function with decreased rhabdomyoma size $(16.8 \times 11.5 \mathrm{~mm})$. At 3 months of age, a tonic-type seizure occurred and right frontal cortical tubers, multifocal white-matter lesions, and subependymal nodules were discovered on brain magnetic resonance imaging (Figures 2(a) and 2(b)). Vigabatrin as an antiepileptic drug was started. Depigmented skin lesions were also found that time on the right shoulder and chest.

At 6 months of age, echocardiography revealed a further decrease in rhabdomyoma size $(13.8 \times 12.1 \mathrm{~mm})$; the lesion occupied a smaller portion (about 50\%) of the mitral annulus (Figure 3(a)). Tricuspid regurgitation and pulmonary hypertension were improved. MR and LA dilatation were not observed. Digoxin was maintained up to 24 months of age. After discontinuation of medication, no further tachyarrhythmias occurred.

At 3 years of age, echocardiography showed a very small $(6.5 \times 2.3 \mathrm{~mm})$, ellipse-shaped rhabdomyoma attached to the MV anterior leaflet without LV inlet obstruction (peak velocity $=0.76 \mathrm{~m} / \mathrm{s}$ ) (Figures $3(\mathrm{~b})$ and $3(\mathrm{c})$ ). At that time, fibroadenomas began to develop on the face. Convulsions were controlled by vigabatrin and topiramate. A developmental delay of about 18 months was apparent.

\section{Discussion}

Although cardiac rhabdomyomas are known to spontaneously regress in patients with tuberous sclerosis, many complications associated with tumor location and size are possible [1-3]. Some patients are very symptomatic, with signs of severe heart failure or valve dysfunction due to blood flow 


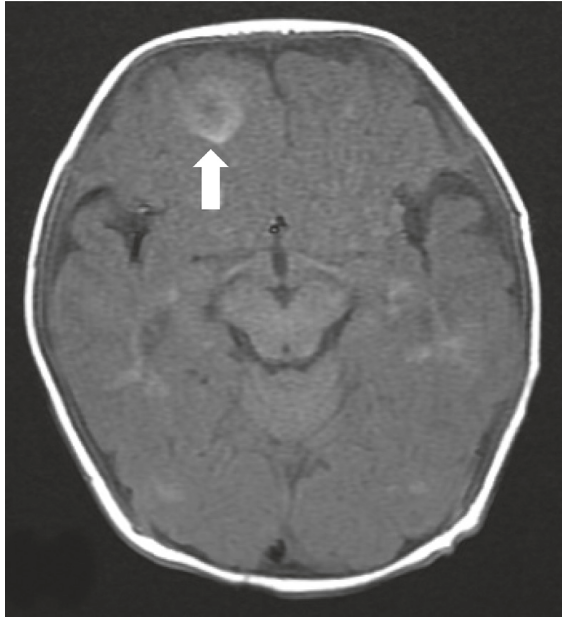

(a)

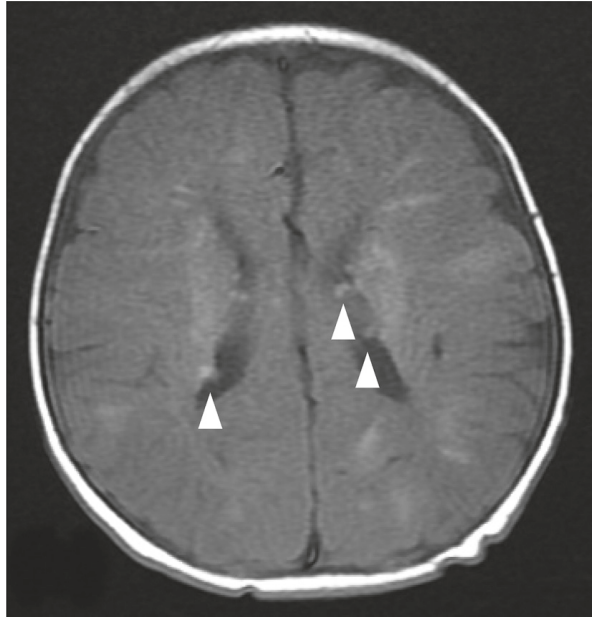

(b)

Figure 2: At 3 months of age, T1-weighted magnetic resonance imaging showed a right frontal cortical tuber (arrow) (a) and high signal intensity lesions in both cerebral hemispheres, with multiple nodular lesions (arrowheads) along the lateral ventricular caudothalamic grooves (b).

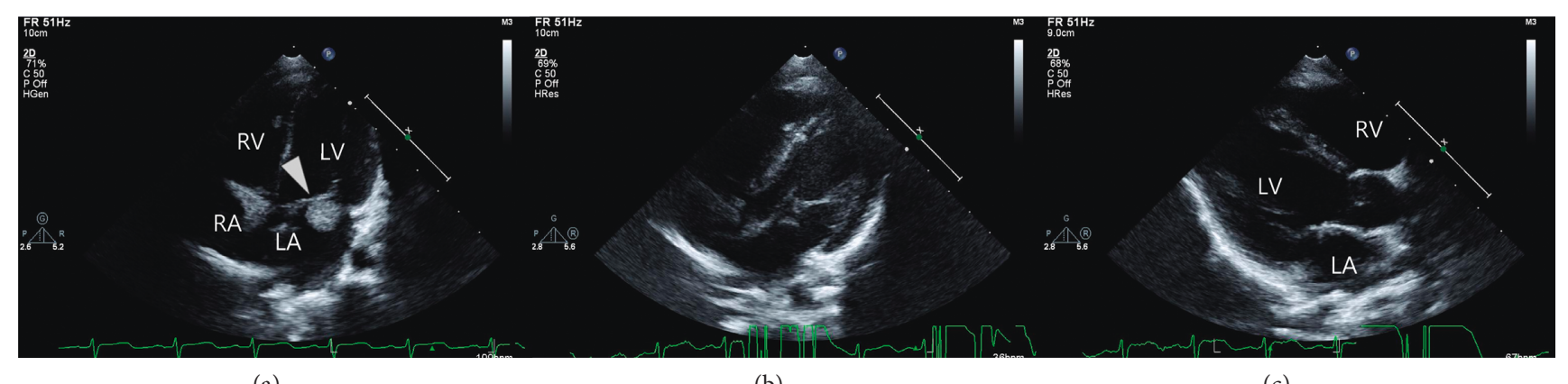

(a)

(b)

(c)

Figure 3: Two-dimensional follow-up echocardiography showed that rhabdomyoma size was significantly decreased at 6 months of age (a). At 3 years of age, a very small $(6.5 \times 2.3 \mathrm{~mm})$, ellipse-shaped rhabdomyoma attached to the MV anterior leaflet without LV inlet obstruction (peak velocity $=0.76 \mathrm{~m} / \mathrm{sec}$ ) (b and $\mathrm{c}$ ) was observed.

obstruction, and even univentricular physiology [7]. Only five case reports of hemodynamically significant LV inflow obstruction caused by cardiac rhabdomyoma have been published (Table 1). Four cases were associated with tuberous sclerosis $[3,7,9,11]$, and most were detected in infancy and the perinatal period. The other case involved a tumor detected in adulthood. Common initial symptoms were related to heart failure, including cyanosis and dyspnea with or without cardiomegaly [9]. Surgical resection of tumor was performed in four patients in whom the lesions were attached to the septum. A 1-day-old infant underwent atrial septostomy by cardiac catheterization due to hemodynamic instability.

In our case, a large rhabdomyoma $(20.5 \times 15.6 \mathrm{~mm})$ occupied $75-90 \%$ of the LV inlet and caused obstruction, LA enlargement, and pulmonary hypertension. The patient did not undergo surgical intervention because he was hemodynamically stable. Since the rhabdomyoma was attached to the anterior leaflet of the MV, there was a risk of valve dysfunction after surgery. With increasing age, the LV inflow obstruction was attenuated by decreasing rhabdomyoma and increasing mitral annulus size. At 3 years of age, the rhabdomyoma had decreased to an ellipseshaped mass $6.5 \times 2.3 \mathrm{~mm}$ in size and showed no LV flow disturbance. Repeat echocardiography to confirm hemodynamic stability played a critical role in determining treatment. Many reports have emphasized the usefulness of echocardiography in the management of cardiac rhabdomyoma in neonates or children. Di Liang et al. [11] described serial echocardiographic evaluation of cardiac rhabdomyoma. Follow-up echocardiography revealed that of 22 tumors in 8 patients, 7 completely regressed, 7 partially regressed, and 8 remained stable. In addition, Batmaz et al. [12] reported a huge spherical rhabdomyoma originating from the MV in an asymptomatic patient with a murmur and experienced spontaneous regression with conservative treatment alone. In the present case, the neonate had an arrhythmia and evidence of congestive heart failure. Hemodynamic stability was confirmed accurately and continuously with echocardiography. Therefore, we provided conservative treatment. 
TABLE 1: Clinical features of patients with significant LV inlet obstruction caused by cardiac rhabdomyoma.

\begin{tabular}{|c|c|c|c|c|c|c|c|c|}
\hline $\begin{array}{l}\text { Reference, } \\
\text { year }\end{array}$ & $\begin{array}{c}\text { Age at } \\
\text { diagnosis }\end{array}$ & $\begin{array}{c}\text { Initial } \\
\text { presentation }\end{array}$ & $\begin{array}{c}\text { Rhabdomyoma } \\
\text { number }\end{array}$ & $\begin{array}{c}\text { Rhabdomyoma } \\
\text { treatment }\end{array}$ & $\begin{array}{c}\text { Spontaneous } \\
\text { rhabdomyoma } \\
\text { regression }\end{array}$ & $\begin{array}{l}\text { Genetic } \\
\text { analysis }\end{array}$ & $\begin{array}{c}\text { Tuberous } \\
\text { sclerosis- } \\
\text { associated sign }\end{array}$ & Outcome \\
\hline $\begin{array}{l}\text { Mair et al., } \\
1977 \text { [7] }\end{array}$ & 1 day & $\begin{array}{c}\text { Cyanosis } \\
\text { Tachypnea } \\
\text { Tachycardia } \\
\text { Cardiomegaly } \\
\text { Hepatomegaly }\end{array}$ & Multiple & $\begin{array}{c}\text { Atrial } \\
\text { septostomy }\end{array}$ & No & None & $\begin{array}{c}\text { Cerebral } \\
\text { hamartoma }\end{array}$ & Died \\
\hline $\begin{array}{l}\text { Muhler et al., } \\
1994 \text { [3] }\end{array}$ & 5 weeks & $\begin{array}{c}\text { Pulmonary } \\
\text { edema }\end{array}$ & 1 & $\begin{array}{l}\text { Tumor } \\
\text { resection }\end{array}$ & No & None & None & Died \\
\hline $\begin{array}{l}\text { Dyamenahalli } \\
\text { et al., } 1998 \text { [8] }\end{array}$ & 1 day & $\begin{array}{c}\text { Cyanosis } \\
\text { Tachycardia }\end{array}$ & 1 & $\begin{array}{l}\text { Tumor } \\
\text { resection }\end{array}$ & No & None & Unknown & Alive \\
\hline $\begin{array}{l}\text { Abdel- } \\
\text { Rahman et al., } \\
2005 \text { [9] }\end{array}$ & Prenatal & $\begin{array}{c}\text { Cyanosis } \\
\text { Cardiomegaly }\end{array}$ & 3 & $\begin{array}{l}\text { Tumor } \\
\text { resection }\end{array}$ & Unknown & None & Unknown & Alive \\
\hline $\begin{array}{l}\text { Ono et al., } \\
2007 \text { [10] }\end{array}$ & 20 years & Dyspnea & Multiple & $\begin{array}{l}\text { Tumor } \\
\text { resection }\end{array}$ & No & None & None & Alive \\
\hline This case & 1 day & $\begin{array}{l}\text { Tachypnea } \\
\text { Tachycardia }\end{array}$ & Multiple & None & Yes & TSC2 & $\begin{array}{c}\text { Depigmented } \\
\text { nevus } \\
\text { Adenoma } \\
\text { sebaceum } \\
\text { Depigmented } \\
\text { retina } \\
\text { Developmental } \\
\text { delay }\end{array}$ & Alive \\
\hline
\end{tabular}

TSC2: tuberous sclerosis 2 .

\section{Conclusion}

Although a cardiac rhabdomyoma can be large enough to induce LV inlet obstruction, conservative treatment without aggressive surgical intervention can be considered if hemodynamic conditions do not deteriorate. In addition, repeated echocardiography may play a pivotal role in understanding hemodynamic status and establishing a treatment plan.

\section{Disclosure}

This case was presented at the poster session of the annual conference of Korean Pediatrics Society held in Seoul, South Korea, on Thursday, November 10, 2016.

\section{Conflicts of Interest}

The authors have no conflicts of interest to disclose.

\section{Acknowledgments}

This study was supported by a grant (NRF2015R1D1A1A01059017) of the Basic Science Research Program through the National Research Foundation of Korea (NRF) funded by the Ministry of Education, Republic of Korea.

\section{References}

[1] W. Tworetzky, D. B. McElhinney, R. Margossian et al., "Association between cardiac tumors and tuberous sclerosis in the fetus and neonate," American Journal of Cardiology, vol. 92, no. 4, pp. 487-489, 2003.

[2] D. G. Holley, G. R. Martin, J. I. Brenner et al., "Diagnosis and management of fetal cardiac tumors: a multicenter experience and review of published reports," Journal of the American College of Cardiology, vol. 26, no. 2, pp. 516-520, 1995.

[3] E. G. Muhler, V. Turniski-Harder, W. Engelhardt, and G. von Bernuth, "Cardiac involvement in tuberous sclerosis," British Heart Journal, vol. 72, no. 6, pp. 584-590, 1994.

[4] T. Hishitani, K. Hoshino, K. Ogawa et al., "Rapid enlargement of cardiac rhabdomyoma during corticotropin therapy for infantile spasms," Canadian Journal of Cardiology, vol. 13, no. 1 , pp. 72-74, 1997.

[5] C. M. Ikemba, B. W. Eidem, V. V. Dimas et al., "Fetal rhabdomyoma causing postnatal critical left ventricular outflow tract obstruction," Annals of Thoracic Surgery, vol. 80, no. 4, p. 1529, 2005.

[6] H. S. Chan, M. J. Sonley, C. A. Moes et al., "Primary and secondary tumors of childhood involving the heart, pericardium, and great vessels. A report of 75 cases and review of the literature," Cancer, vol. 56, no. 4, pp. 825-836, 1985.

[7] D. D. Mair, J. L. Titus, G. D. Davis, and D. G. Ritter, "Cardiac rhabdomyoma simulating mitral atresia," Chest, vol. 71, no. 1, pp. 102-105, 1977.

[8] U. Dyamenahalli, M. D. Black, C. Boutin et al., "Obstructive rhabdomyoma and univentricular physiology: a rare combination," Annals of Thoracic Surgery, vol. 65, no. 3, pp. 835837, 1998.

[9] U. Abdel-Rahman, F. Ozaslan, A. Esmaeili, and A. Moritz, "A giant rhabdomyoma with left ventricular inflow occlusion and univentricular physiology," Thoracic and Cardiovascular Surgeon, vol. 53, no. 4, pp. 259-260, 2005. 
[10] M. Ono, D. Boethig, E. Akin et al., "Coexistent cardiac rhabdomyoma with mitral valve anomaly in patients with tuberous sclerosis: a case report," Thoracic and Cardiovascular Surgeon, vol. 55, no. 2, pp. 120-121, 2007.

[11] C. Di Liang, S. F. Ko, and S. C. Huang, "Echocardiographic evaluation of cardiac rhabdomyoma in infants and children," Journal of Clinical Ultrasound, vol. 28, no. 8, pp. 381-386, 2000.

[12] G. Batmaz, R. Besikci, G. Arslan, I. Kafadar, and G. Ahunbay, "Spontaneous regression of huge cardiac rhabdomyoma in an infant," Images in Paediatric Cardiology, vol. 2, no. 4, pp. 4-10, 2000 . 


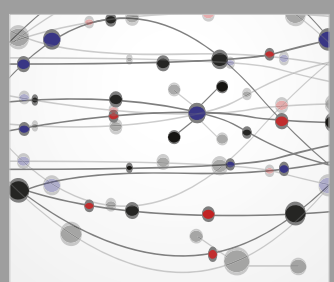

The Scientific World Journal
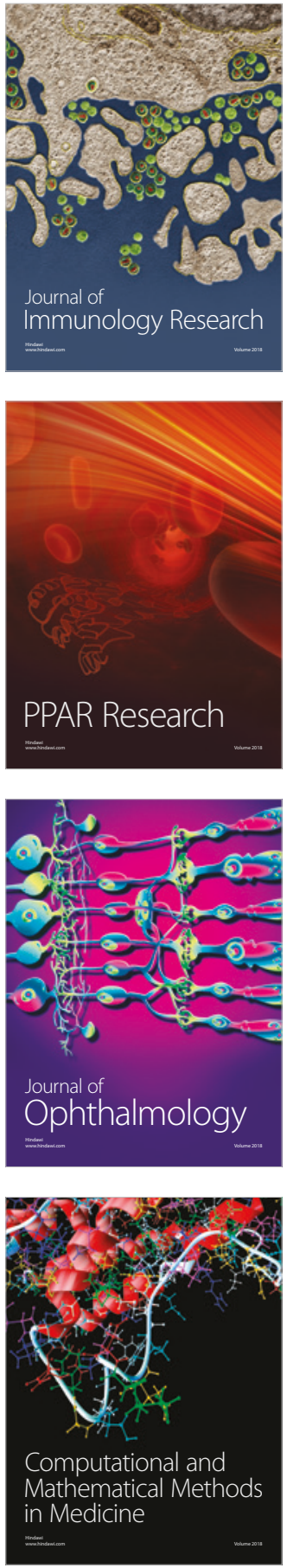

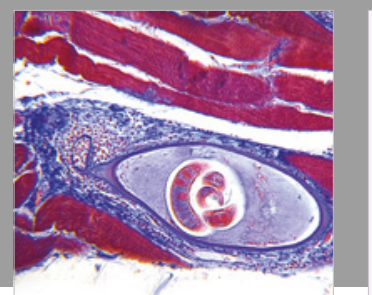

Gastroenterology Research and Practice

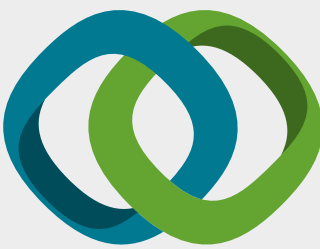

\section{Hindawi}

Submit your manuscripts at

www.hindawi.com
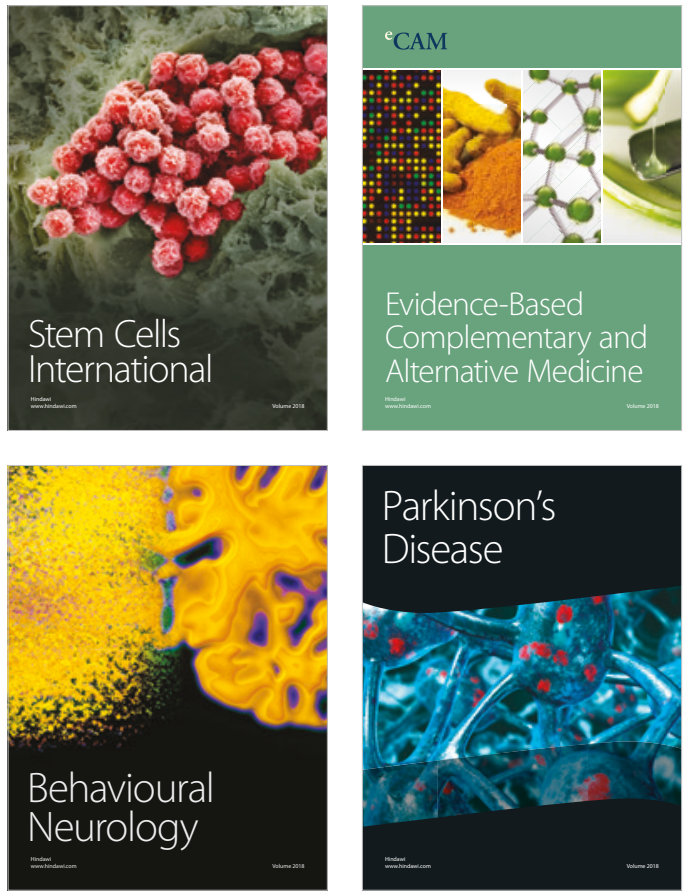

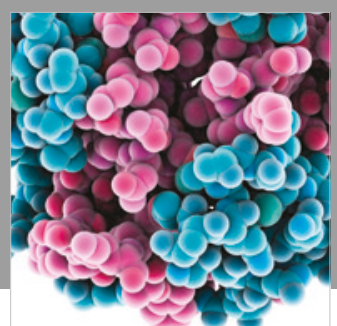

ournal of

Diabetes Research

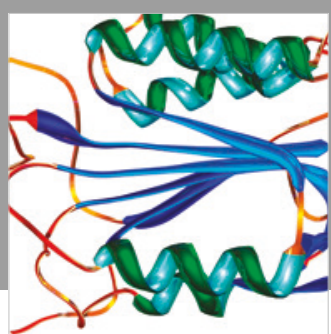

Disease Markers
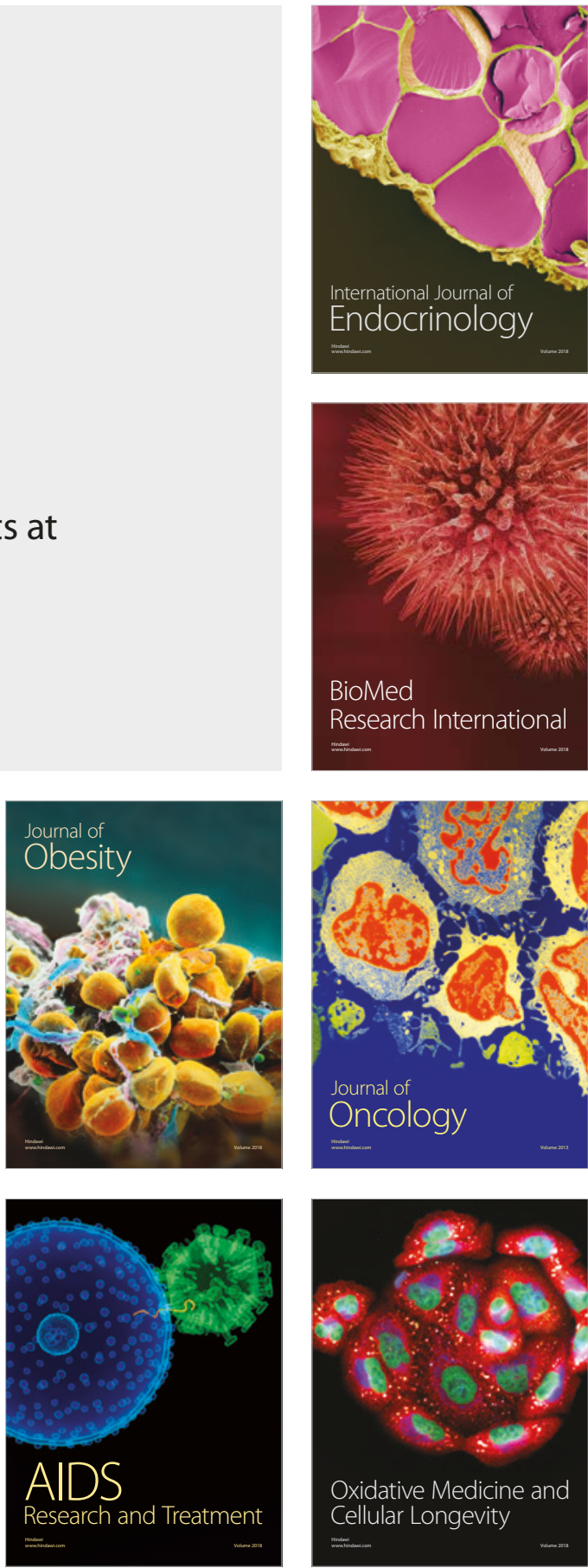